\title{
Instituições de longa permanência para idosos: um estudo sobre a necessidade de vagas ${ }^{*}$
}

\author{
Mirela Castro Santos Camargos ${ }^{* *}$
}

\section{Introdução}

Considerado uma das mais significativas tendências do século XXI, o envelhecimento populacional já não é tido como uma novidade. No mundo, uma em cada nove pessoas tem 60 anos ou mais, com o crescimento estimado para uma em cada cinco em 2050 (UNFPA, 2012). Segundo os dados do Censo Demográfico de 2010, 10,8\% da população brasileira é composta por pessoas acima de 60 anos.

A relação entre o idoso que potencialmente demanda assistência e o potencial cuidador informal de idosos, que quase sempre é um familiar, tende a ficar cada vez mais desproporcional, devido ao envelhecimento da população, mesmo considerando um cenário mais otimista (FERREIRA, 2007). O indicador razão de suporte, por exemplo, que reflete a relação demográfica entre pessoas que são potenciais cuidadores (entre 50 e 60 anos) e os que, em geral, precisam de cuidados (75 anos e mais), mostra que, em 2050, haverá apenas dois potenciais cuidadores para cada idoso de 75 anos e mais, enquanto em 2000 existiam cinco (RIPSA, 2009).

O aumento da participação relativa dos idosos na população gera a necessidade de atendimento de novos tipos de demandas e, com isso, a criação de vagas em determinados serviços públicos, como, por exemplo, os de acompanhamento, abrigamento e saúde de idosos (FERREIRA et al., 2012).

No Brasil, ainda existem poucos programas formais por parte do Estado para prestar assistência aos idosos que não podem contar com auxílio da família, ou que não possuem recursos financeiros e necessitam de apoio. Um exemplo de inciativa recente é o projeto

\footnotetext{
* A autora agradece à Fundação de Amparo à Pesquisa do Estado de Minas Gerais (Fapemig) pelo apoio para publicação deste artigo.

** Fundação João Pinheiro, Belo Horizonte-MG, Brasil (mirelacsc@gmail.com).
} 
Cuidador de Idosos do Programa Maior Cuidado, implantado pela prefeitura de Belo Horizonte (MG), que consiste no acompanhamento domiciliar da rotina de idosos semidependentes e dependentes em situação de vulnerabilidade social pela fragilização de vínculos familiares e sociais e pela ausência de acesso a possibilidades de inserção, habilitação social e comunitária (PREFEITURA MUNICIPAL DE BELO HORIZONTE, 2011). A institucionalização é a modalidade de serviço mais conhecida e principal alternativa entre as não familiares para idosos que precisam de cuidados de longa duração (CAMARGOS; RODRIGUES; MACHADO, 2011).

Apesar do aumento da demanda por instituições de longa permanência para idosos (ILPI), a imagem negativa destes estabelecimentos ainda permanece bastante arraigada no imaginário das pessoas. Parte deste preconceito talvez possa ser atribuída ao seu processo histórico de constituição, uma vez que tais instituições surgiram para abrigar pessoas em situação de pobreza, sem suporte da família e com problemas de saúde. Pollo e Assis (2008) lembram que, quando não existiam instituições específicas, os idosos eram abrigados em asilos de mendicidade, juntamente com outros pobres, doentes mentais, crianças abandonadas e desempregados. Atualmente, o cenário é bem diferente, mas estas instituições infelizmente ainda estão longe dos padrões de qualidade desejáveis. Segundo as autoras, ainda se sabe pouco sobre a demanda por institucionalização e sobre o número de idosos institucionalizados. Entretanto, pode-se afirmar que não há sinais de que esta demanda irá diminuir, principalmente se não forem criadas alternativas para atender idosos.

Para Camarano (2008), a legislação brasileira (Constituição Federal de 1988 e Política Nacional do Idoso de 1994), que estabelece que a família é a principal responsável pelo cuidado do idoso, reforça o preconceito quanto ao cuidado institucional. Isso justificaria o fato de a residência em ILPI não ser uma prática comum no Brasil. Neste caso, em geral, o público-alvo dessas instituições são indivíduos em idade mais avançada, com redução na capacidade funcional, em situação financeira precária, sem família e/ou em condições de maus-tratos familiares.

O Ipea realizou um estudo em todas as regiões do país sobre a população de 60 anos e mais residente em ILPI (IPEA, 2010). Em Minas Gerais foram identificadas 683 ILPI, distribuídas em 476 municípios dos 853 existentes, que abrigam cerca de 1\% do total da população idosa mineira.

Ainda que o cenário atual aponte para uma maior necessidade de ILPI, sabe-se que a realidade é bastante diferente. O número destas instituições permanece pequeno se considerado o processo de envelhecimento populacional. Diante do exposto, o objetivo deste estudo é analisar a necessidade de vagas em ILPI em Minas Gerais, segundo informações das instituições já existentes.

\section{Metodologia}

Este estudo, de natureza descritiva e exploratória, utilizou dados de duas pesquisas coordenadas pela Fundação João Pinheiro (FJP) e financiadas pela Fundação de Amparo 
à Pesquisa de Minas Gerais (Fapemig) em instituições de longa permanência para idosos (ILPI) de Minas Gerais.

A primeira pesquisa, intitulada "População Idosa na Região Metropolitana de Belo Horizonte: um estudo sobre a institucionalização de longa permanência”, realizou um levantamento de campo em 105 ILPI da Região Metropolitana de Belo Horizonte (RMBH). Foi feito um censo com todas as instituições localizadas naquela região no período, com entrevistas entre março e julho de 2011, em 24 municípios. A segunda, denominada "A População Idosa em Minas Gerais: um estudo sobre a institucionalização de longa permanência”, ampliou a pesquisa para o Estado, porém sem representatividade estatística dadas as restrições orçamentárias. Foram contempladas as dez regiões de planejamento de Minas Gerais, com um levantamento de campo em 22 municípios, incluindo visita a 30 ILPI do interior do Estado, em julho de 2013. As pesquisas da FJP pretendiam caracterizar as ILPI, em relação a aspectos como: natureza jurídica (filantrópica ou particular); fonte de recursos financeiros; número de idosos atendidos; capacidade de atendimento; profissionais; serviços prestados; atenção à saúde; rotina; normas de funcionamento; e infraestrutura.

Nas duas pesquisas utilizaram-se os mesmos instrumentos para coleta de dados. No presente estudo, foram avaliadas as informações referentes à presença de fila de espera para receber novos residentes e suas características, incluindo todas as ILPI ( $n=135)$. Apesar de reconhecer as limitações ao se empregarem dados de dois momentos distintos, afinal a oferta de vagas pode sofrer variações, acredita-se que o intervalo entre as pesquisas pode ser considerado curto e as informações coletadas podem auxiliar na discussão sobre a necessidade de vagas em diferentes regiões.

Nas análises que se seguem, por questões práticas, utilizam-se apenas duas divisões para as ILPI: filantrópicas e privadas. As primeiras englobam as instituições privadas filantrópicas (religiosas e não religiosas) e as municipais (apenas duas na amostra). Já a segunda categoria diz respeito às ILPI privadas com fins lucrativos. Dadas as características dos municípios de localização das ILPI, foram criados, para a análise, três grupos: Belo Horizonte; demais municípios da RMBH (exclui-se Belo Horizonte); e municípios do interior (exclui-se a RMBH). Seguindo esses critérios, a amostra conta com 68 ILPI (42 privadas e 26 filantrópicas) em Belo Horizonte, 37 (duas privadas e 35 filantrópicas) nos demais municípios da RMBH e 30 (quatro privadas e 26 filantrópicas) no interior de Minas Gerais. No conjunto dessas instituições, residiam 4.041 idosos (1.369 homens e 2.672 mulheres), sendo que apenas uma ILPI era exclusiva para homens e 25 exclusivas para mulheres. A maioria das instituições $(80,7 \%)$ era mista, com dormitórios separados por sexo.

Do total de ILPI investigadas, 15,6\% declararam que não cobravam mensalidade dos residentes ou de seus familiares. Nas demais, o valor das mensalidades, avaliado em salários mínimos (SM) na época da pesquisa, variou de 0,7 a 9,2 SM em Belo Horizonte, de 0,3 a 4 SM nos demais municípios da RMBH e de 0,4 a 5 SM no interior de Minas Gerais. 


\section{Resultados}

A maioria das ILPI (60,7\%) relatou que possui listas de espera (Tabela 1), sendo essas exclusivas para pessoas idosas. Nesse caso, os interessados em vagas têm os nomes, contatos e características dos idosos anotados.

Em Belo Horizonte, 73,1\% das ILPI filantrópicas apresentavam listas de espera, contra apenas 47,6\% das privadas. Já nos demais municípios que compõem a RMBH, nenhuma instituição privada relatou contar com a lista, ao passo que 68,6\% das filantrópicas afirmaram que sim. Nas demais cidades do interior, em 69,2\% das filantrópicas visitadas e em $25 \%$ das privadas existia a fila de espera.

TABELA 1

Instituições de longa permanência para idosos (ILPI) que possuem listas de espera para receber novos residentes, segundo a natureza

Estado de Minas Gerais - 2011-2013

Em porcentagem

\begin{tabular}{lcccc}
\hline \multicolumn{1}{c}{ Natureza } & Belo Horizonte & $\begin{array}{c}\text { Região } \\
\text { Metropolitana de } \\
\text { Belo Horizonte (3) }\end{array}$ & Interior (4) & Total \\
\hline Filantrópicas (1) $(n=87)$ & 73,1 & 68,6 & 69,2 & 70,1 \\
Privadas (2) $(n=48)$ & 47,6 & 0,0 & 25,0 & 43,8 \\
Total $(n=135)$ & 57,4 & 64,9 & $\mathbf{6 3 , 3}$ & $\mathbf{6 0 , 7}$ \\
\hline
\end{tabular}

Fonte: Fundação João Pinheiro. Pesquisas “População Idosa na Região Metropolitana de Belo Horizonte: um estudo sobre a institucionalização de longa permanência” (2011) e "A População Idosa em Minas Gerais: um estudo sobre a institucionalização de longa permanência" (2013).

(1) Englobam as ILPI privadas filantrópicas (religiosas e não religiosas) e as municipais.

(2) Referem-se às ILPI privadas com fins lucrativos.

(3) Exclui o município de Belo Horizonte.

(4) Exclui a RMBH.

Foram comuns os relatos de longas listas de espera entre as entidades filantrópicas, uma delas, inclusive, no interior de Minas, com mais de 100 pessoas aguardando por uma vaga. Analisando por município, dos 46 investigados, apenas em dez deles as instituições negaram a existência de lista. Nos demais municípios, pelo menos uma ILPI mencionou o cadastro de espera. Em Belo Horizonte, por exemplo, 57,4\% mencionaram a lista de reserva.

Em relação à dinâmica da fila de espera, segundo relatos dos entrevistados, observou-se que, na prática, essa ordem de cadastramento não era respeitada. Nas ILPI filantrópicas, a admissão do idoso, quando surgia uma nova vaga, dependia da avaliação da vulnerabilidade socioeconômica e de sua situação de saúde. Neste caso, o grau de dependência funcional pareceu ser determinante na escolha em ILPI localizadas em Belo Horizonte e em sua região metropolitana, sendo que em alguns locais havia preferência por pessoas independentes. Já no interior de Minas Gerais, o maior grau de dificuldade financeira pareceu ser o principal fator utilizado no momento da triagem para uma nova vaga. Um exemplo da preferência por aqueles que possuem maior dificuldade financeira foi relatado em uma ILPI filantrópica, na qual as 15 pessoas que estavam na lista de espera 
já foram pré-selecionadas pelo seu perfil socioeconômico. Cabe destacar que, segundo informado, em situações de encaminhamento judicial o idoso passava a ter prioridade.

No caso da dependência funcional, alguns entrevistados de Belo Horizonte e de sua região metropolitana mencionaram que, apesar de constarem na lista de espera, não se aceitavam idosos com grau de dependência III, ou seja, aqueles que necessitam de ajuda em todas as atividades de autocuidado. Isso ocorria, de acordo com os entrevistados, porque esses idosos eram considerados mais onerosos e, além disso, ao longo dos anos aqueles que já residiam na instituição tenderiam a evoluir para esse nível de dependência, permanecendo no local. Em uma ILPI, foi mencionado que, embora se aceitassem todos os níveis de dependência, a opção por idosos totalmente dependentes só ocorria quando surgisse uma vaga de um residente que estava nas mesmas condições.

Independentemente da existência ou não de lista de espera por vaga, em análise de outras questões do questionário, observa-se que praticamente uma em cada três ILPI investigadas possuía critérios de seleção por dependência, 9,7\% só aceitavam idosos independentes e 20,1\% apenas idosos independentes ou semidependentes (necessitam de ajuda em até três atividades de autocuidado). Ainda em relação aos critérios de admissão por características de saúde, 48,1\% das ILPI não recebiam para novas vagas idosos com demências e 52,2\% recusavam novos residentes que apresentassem determinadas doenças, com destaque para as infecto-contagiosas (33,6\%).

\section{Conclusão}

Ainda que as informações obtidas neste estudo digam respeito apenas à percepção das instituições já existentes, pode-se observar que já há uma necessidade real na oferta de vagas para idosos nas ILPI. Isso ficou evidente não só pelo relato das listas de espera, mas principalmente pela adoção de critérios de seleção. A triagem para admissão evidencia, por um lado, que a grande demanda por este tipo de serviço permitia que as instituições elegessem apenas o perfil desejado e, por outro, que existiam pessoas que dificilmente seriam admitidas.

A não admissão de pessoas com dependência grave merece destaque, afinal, idosos com este tipo de incapacidade são os que demandam mais atenção e investimentos financeiros. Apesar de o envelhecimento não significar que o idoso irá apresentar doenças, incapacidades e dependência, sabe-se que, nas idades avançadas, são maiores as prevalências de doenças crônicas e incapacidades funcionais. Segundo Camargos, Machado e Rodrigues (2008), em 2003, no Brasil, ao completar 60 anos, as mulheres poderiam esperar viver, em média, 4,0 anos com incapacidade funcional grave (com dificuldade ou dependência para comer, tomar banho e ir ao banheiro). Nesta mesma idade, a expectativa de vida com incapacidade funcional grave para os homens era 2,5 anos. Nesse estudo, os autores já mencionavam a necessidade de criar alternativas para o cuidado dos idosos dependentes e a importância de pensar medidas que favorecessem a ampliação dos anos a serem vividos livres de incapacidade funcional. 
Em 1994, Chaimowicz e Greco (1999) realizaram um estudo em 40 ILPI em Belo Horizonte, com a pretensão de discutir a dinâmica da institucionalização de idosos. Para os autores, ILPI lotadas, com filas de espera e critérios rígidos de admissão (metade recusava idosos com demências ou dependentes) indicariam uma dificuldade de acesso a essas instituições, contribuindo para a baixa taxa de institucionalização. Os autores supunham que, já naquela época, provavelmente, as famílias evitavam ou retardavam a institucionalização não só por laços afetivos, mas também pela dificuldade de acesso a uma vaga. Passados quase 20 anos, as filas de espera e os critérios de admissão para aqueles idosos considerados mais frágeis ainda permanecem em Belo Horizonte, assim como em outros municípios mineiros investigados.

Mesmo que ocorram melhorias na saúde da população, permitindo que as pessoas envelheçam com autonomia e independência, o envelhecimento populacional, associado ao aumento da expectativa de vida e aos novos arranjos familiares, tende a ampliar ainda mais a demanda por vagas nessas instituições. Resta agora pensar no que fazer com a demanda atual e planejar o futuro, em um momento em que, para cada cinco pessoas, uma será idosa.

Contudo, algumas limitações deste trabalho devem ser ressaltadas. Esta foi uma tentativa de discutir a necessidade de vagas nas ILPI, porém, apenas com os dados existentes não se pode estimar a demanda real, o que exigiria dados mais específicos, associados a projeções da população. A análise tenta medir esta necessidade pela falta de vagas nas instituições existentes, ou seja, na oferta reduzida. Cabe destacar que a demanda é ocasionada pelo crescimento da população em situação de fragilidade econômica, física, mental, cognitiva e familiar, o que deve ser considerado em trabalhos futuros.

Finalmente, este estudo reforça a necessidade de expansão da oferta de ILPI e a importância de repensar a assistência aos idosos com maior grau de dependência.

\section{Referências}

CAMARANO, A. A. Cuidados de longa duração para a população idosa: família ou instituição de longa permanência? Sinais Sociais, v. 7, n. 3, p. 10-39, 2008.

CAMARGOS, M. C. S.; MACHADO, C. ..; RODRIGUES, R. N. Life expectancy among elderly Brazilians in 2003 according to different levels of functional disability. Cad. Saúde Pública, v. 24, n. 4, p. 845-52, 2008.

CAMARGOS, M. C. S.; RODRIGUES, R. N.; MACHADO, C. J. Idoso, família e domicílio: uma revisão narrativa sobre a decisão de morar sozinho. Revista Brasileira de Estudos de População, v. 28, n. 1, p. 217230, 2011.

CHAIMOWICZ, F.; GRECO, D. B. Dinâmica da institucionalização de idosos em Belo Horizonte, Brasil. Rev. Saúde Pública, v. 33, n. 5, p. 454-460, 1999.

FERREIRA, A. R. S. Perspectivas da oferta de cuidadores informais da população idosa, Brasil 2000-2015. Dissertação (Mestrado em Demografia) - Centro de Desenvolvimento e Planejamento Regional, Universidade Federal de Minas Gerais, Belo Horizonte, 2007.

FERREIRA, F. P. M.; MIRANDA-RIBEIRO, A.; RIANI, J. L. R.; MARINHO, K. R. L.; CAMARGOS, M. C. S. População e políticas: tendências e cenários para Minas Gerais. Cadernos BDMG, n. 21, outubro de 2012. 
FUNDO DE POPULAÇÃO DAS NAÇÕES UNIDAS (UNFPA). Envelhecimento no século XXI: celebração e desafio (Resumo Executivo). Nova York, 2012.

IPEA. Características das instituições de longa permanência para idosos - Região Sudeste. Rio de Janeiro: Ipea, 2010.

PREFEITURA MUNICIPAL DE BELO HORIZONTE. Programa Maior Cuidado inova em atendimento aos idosos da capital. 2011. Disponível em: <http://portalpbh.pbh.gov.br/pbh/ecp/noticia. do? evento=portlet $\& A \mathrm{p}=$ not\&idConteudo=45805\&pldPlc=\&app=salanoticias $>$. Acesso em: 06 abr. 2014.

POLLO, S. H. L.; ASSIS, M. Instituições de longa permanência para idosos - ILPIS: desafios e alternativas no município do Rio de Janeiro. Revista Brasileira de Geriatria e Gerontologia, v. 11, n. 1, p.1-18, 2008.

RIPSA. Demografia e saúde: contribuição para análise de situação e tendências. Brasília, 2009.

\section{Autora}

Mirela Castro Santos Camargos é doutora em Demografia pela Universidade Federal de Minas Gerais. Pesquisadora e professora na Fundação João Pinheiro.

\section{Endereço de correspondência}

Mirela Castro Santos Camargos

Alameda das Acácias, 70, sala 326C, Bairro São Luiz

Belo Horizonte, MG - CEP 31275-150

Recebido para publicação em 09/11/2013

Aceito para publicação em 26/03/2014 
